\title{
Losing your nerve
}

The Smads are a family of proteins with functions that include the transduction of signalling by the transforming growth factor- $\beta$ superfamily, which includes the bone morphogenetic proteins (BMPs). In Developmental Cell, LeSueur et al. report that Smad10, a newly identified Smad in Xenopus, is essential for the formation of the frog nervous system.

Smad10 seems to belong to the class of molecules known as common Smads (co-Smads), which associate with receptorregulated Smads (R-Smads). These, in turn, interact directly with TGF- $\beta$ ligand-receptor complexes. The only other known co-Smad is Smad4, which is structurally very similar to Smad10. To analyse the function of Smad10, the authors used two loss-of-function approaches - they injected Xenopus embryos with a dominant-negative form of Smad10 or with an antisense oligonucleotide. In both cases, the embryos failed to develop a neural tube.

LeSueur et al. then tested the effects of Smad10 inhibition on the activity of two neural inducers - fibroblast growth factor
(FGF), which induces posterior neural tissue, and the BMP inhibitor noggin, which induces anterior neural tissue - in uncommitted ectodermal tissue explants. They found that inhibiting Smad10 prevented the activation of posterior neural markers by FGF, and of anterior neural markers by noggin. So, Smad10 is required for the induction of both anterior and posterior neural tissue, by mediating FGF and noggin activity, respectively. The mechanism that is responsible for this dual response has not been fully elucidated, although initial findings indicate that the phosphorylation state of Smad10 is a key factor.

The implications of these findings for other species are not yet known, and no Smad10 homologue has been identified in the mouse or the chick. However, previous studies in mice indicated that Smad4 might not be the only molecule with co-Smad activity, so it is expected that molecules that are functionally — if not structurally — equivalent are waiting to be discovered.

Heather Wood

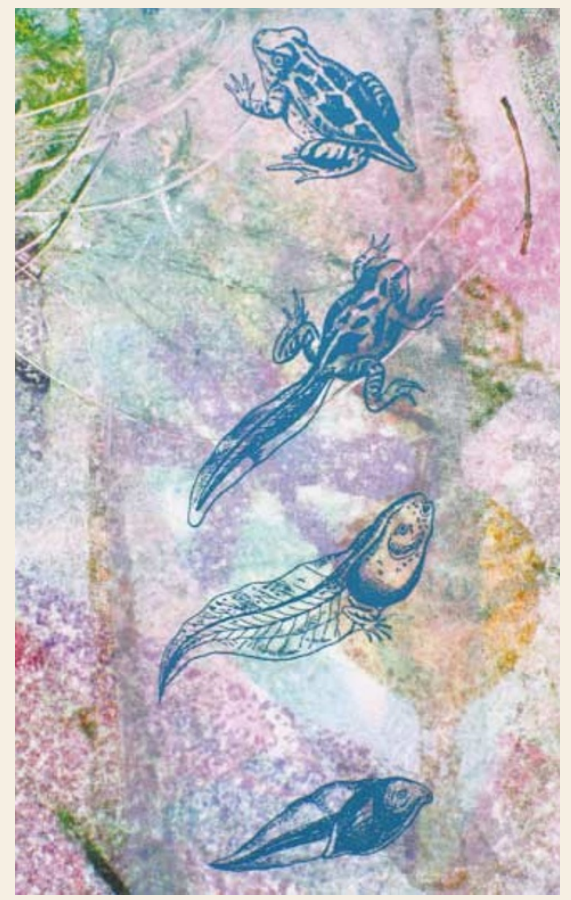

(7) References and links ORIGINAL RESEARCH PAPER LeSueur, J. A. et al. Smad10 is required for formation of the frog nervous system. Dev. Cell $\mathbf{2}$, 771-783 (2002)

FURTHER READING Muñoz-Sanjuán, I. \& Brivanlou, A. H. Neural induction, the default model and embryonic stem cells. Nature Rev. Neurosci. 3, 271-280 (2002)

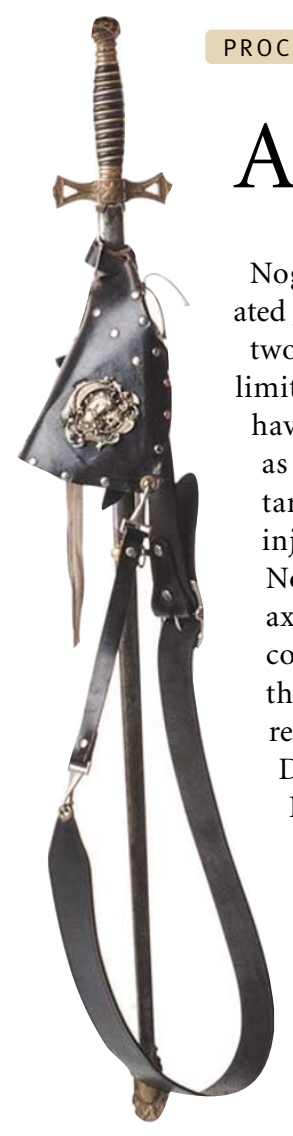

\section{All for one, one for all}

Nogo and myelin-associated glycoprotein (MAG) two myelin proteins that imit axon regeneration have received attention as possible therapeutic targets after spinal cord injury. The action of Nogo depends on its axonal receptor, $\mathrm{NgR}$. By contrast, the identity of the MAG receptor has remained a mystery. Now Domeniconi et al. and Liu et al. report that MAG also binds to $\mathrm{NgR}$, and that this interaction mediates its inhibitory effect on axon outgrowth.

The two studies show that MAG and $\mathrm{NgR}$ interact directly and that disrupting this interaction prevents MAG from inhibiting axonal growth. In addition, Liu et al. found that expressing $\mathrm{NgR}$ conferred MAG sensitivity on otherwise insensitive neurons.

Although the findings from both groups agree in general terms, they differ in one important respect; whereas Domeniconi et al. found that Nogo and MAG compete for the same site on NgR, Liu et al. obtained evidence for independent binding sites on the receptor. It will be important to resolve this difference, as the existence of more than one binding site might have implications for the design of molecules that aim to block the inhibitory action of $\mathrm{NgR}$.

Meanwhile, a third paper reports on yet another protein that binds to $\mathrm{NgR}$ - oligodendrocyte-myelin glycoprotein (OMgp). Wang et al. showed that this previously identified protein also inhibits neurite outgrowth in a NgR-dependent way, and that receptor expression confers OMgp responsiveness on insensitive neurons. Moreover, Wang et al. found that OMgp and Nogo bind to overlapping sites on NgR.

So, three myelin proteins that inhibit axon outgrowth share the same receptor. This fact compels us to take a closer look at the intracellular processes downstream of $\mathrm{NgR}$. Intriguingly, the inhibitory effect of myelin is blocked if the small GTPase Rho is inactivated or if cyclic AMP is elevated, pointing to these signalling molecules as possible transducers of the NgR signal. However, NgR is not a transmembrane protein; it is anchored to the membrane by a glycosylphosphatidylinositol link. So, how is the binding of Nogo, MAG and OMpg transduced to the inside of the cell? We still need to discover further molecules that interact with the receptor, linking it to its intracellular signalling pathways.

Juan Carlos López

\section{(2) References and links} ORIGINAL RESEARCH PAPERS

Liu, B. P. et al. Myelin-associated glycoprotein as a functional ligand for the Nogo-66 receptor. Science 27 June 2002 (doi:0.1126/science.1073031) | Domeniconi, M. et al. Myelinassociated glycoprotein interacts with the Nogo66 receptor to inhibit neurite outgrowth. Neuron 28 June 2002

(doi:10.1016/S0896627302007705) | Wang, K. C et al.

Oligodendrocyte-myelin glycoprotein is a Nogo receptor ligand that inhibits neurite outgrowth. Nature 16 June 2002 (doi:10.1038/nature00867) 